filled with strunous material. This I gouged out and stuffed with lint. The boy made a good recovery, and soon got about again with a high boot.

June, 1860. (Two years after the operation.)-The boy is well and strong, and gets about admirably with a high boot. There is still a sinus over the head of the tibia which discharges occasionally, but otherwise he has no trouble with it, and no pain at all. He continues to wear a gutta-percha splint, by his own desire, since I do not think it at all necessary, the anchylosis being perfectly firm. The boy does not appear to have grown much, but not having previously measured him $I$ cannot speak with certainty. The measurements at the present time are-Height: $4 \mathrm{ft}$. 6 in. Right side: From anterior superior spine to lower end of femur, 13in.; from the last point to inner malleolus, $10 \frac{1}{2}$ in. Left side: From anterior superior spine to lower end of femur, 11 in. ; from the last point to inner malleolus, 10 in. Thus the difference is exactly $2 \frac{1}{2}$ in., and depends, as nearly as can be ascertained, upon a shortening of two inches of the femur and half an inch of the tibia. The heel of the boot he wears is two inches and a half in depth.

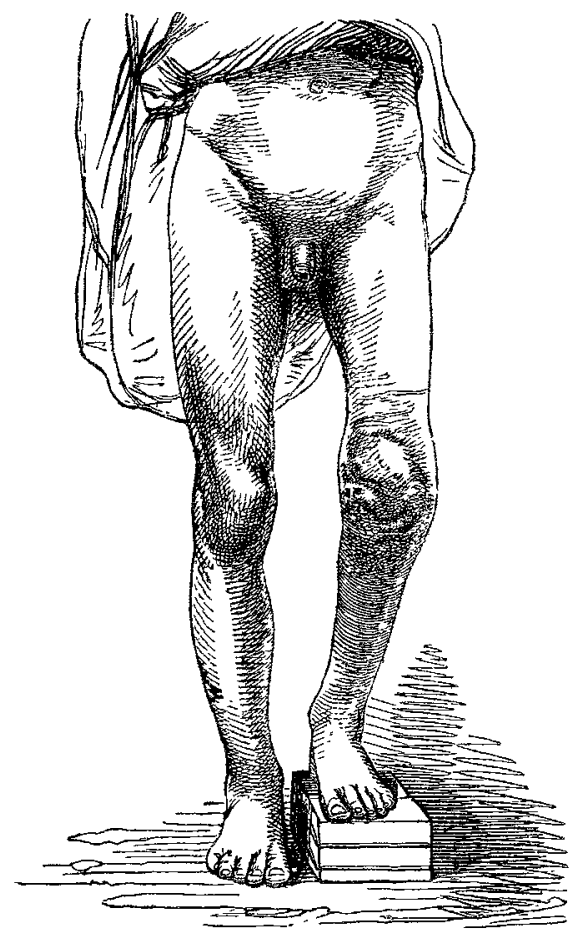

The accompanying sketch is from o photograph, and care was taken to have the pelvis perfectly level, while the amount of shortening is indicated on the block under the foot. The limb is not, perhaps, so perfectly straight as some that have been seen; but it must be borne in mind that the operation and treatment were conducted in a front kitchen, and under every disadvantage as to attendance, \&c.

I could have wished that, instead of a second slice of femur, I had removed a further portion of tibia, thereby possibly pre. venting the abscesses, \&c.; but at the time of the operation the surgeon's attention had not been so forcibly called to the advisability of leaving the epiphysis of the femur as has since been the case. I shall endeavour to keep an eye upon my patient, so as to ascertain and report upon the effects of further growth.

Sackville-street, June, 1860

Therapeutic Use of Aqueous Vapouk of Medicinai SolUTIONS PROJECTED INTO THE BRONCHI.-M. Sales-Girons has of late been perseveringly advocating an ingenious apparatus of his, wherewith solutions of medicinal substances are minutely divided by pneumatic compression, and projected into the trachea. The apparatus was originally employed in order to bring mineral waters into contact with the respiratory mucous membrane; but its use has been extended as above mentioned, and, as it would seem, with satisfactory results. The author is, however, anxious, when the bronchi are acted upon, that his own apparatns, made by $M$. Charrière, should have the preference over a more recent one, wherewith the aqueous vapour, finely divided, is insuffated, as he holds that the oxygen of the air is too stimulating for the respiratory mucous membrane. At all events, it is worthy of note that Professor Trousseau has had much success, in cases of diphtheria, in projecting against the fauces the vapour of a solution of one part of tannin to two parts of alum.
A setlitror

OF THE PRACTICE OF

\section{MEDICINE AND SURGERY IN THE}

HOSPITALS OF LONDON.

Nulla est alia pro certo noscendi via, nisi quam plurimas et morborum et dissectionum historias, tam aliornm proprias, collectas habere $\epsilon$ inter se comparare.-Morgagri. De Sed. et Caus. Morb., lib. 14. Proœmium.

\section{ST. MARY'S HOSPITAL.}

ASCITES ORIGINATING WITHOUT ANY RECOGNISED CATSE, AND YIELDING TO THE EMPLOYMENT OF TONICS.

(Under the care of Dr. HANDField JoNEs.)

Ascites unconnected with renal, hepatic, or peritoneal disease is certainly not of common occurrence. Dr. Copland notices asthenic or passive ascites as one of the idiopathic varieties, but states that it is usually attended with cedema of the ankles, feet, and legs. He recommends, besides other means, opium with diuretics and tonics. The causc mor $b i$ in the following case may have been scarlatinal poison, but the state of the urinary secretions is unfavourable to that view.

Stephen J. C_- a boy, aged three years and a half, whose parents were not in distressed circumstances, but rather the reverse, was admitted into St. Mary's Hospital on May 9th, 1859. He had been ill three weeks; his abdomen had enlarged gradually without pain or tenderness, and no other sign of disease was noticed previously. His appetite had been bad all the time, and he had emaciated much. Another child had died lately, in two days, with enlarged abdomen. He had been under the care of a practitioner, who had wished to perform paracentesis, to which the mother was afraid to consent. The tongue was clean; bowels relaxed five or six times a day. The heart's sounds were normal, and there was good breathing in both backs. The feet and legs were not swollen. The abdomen was considerably distended, dull, and fluctuating; resonance perceived only in the epigastrium; the upper side in lateral decubitus did not become resonant. The liver did not project below the ribs. To have grey and Dover's powder, two grains of each, three times a day, and also small doses of the iodide and nitrate of potass in carraway-water as frequently.

May 12th. - The urine was examined, and noted as scanty, lateritious, and free from albumen. The powders were changed for mercurial ointment, to be rubbed on the abdomen, and a saline mixture containing acetate of potassa and nitric ether with tincture of digitalis (three minims) was ordered, four times a day.

16th. - Tongue clean; skin cold; pulse weak; bowels relaxed, with green stools, till he had some astringent powders; urine scanty and thick; abdomen distended as before. He was now ordered infusion of digitalis and scoparia with acetate of po tassa and nitric ether, and compound tincture of iodine to the abdomen.

On the 18th, as there was no improvement, a trial was made of one-sixth of a grain of tartar emetic thrice a day, and a blister applied to the loins. This was done with the view of re. lieving renal congestion, which seemed probable, as the diuretics produced no good effect. This also failed, and on the 21st, on account of restlessness at night, he was ordered to have one grain of disulphate of quinine at bedtime, and no other medicine.

23rd.-Much more cheerful; appetite better; sleeps very soundly, but perspires then very much. Urine very alkaline, scanty, and thick; deposits phosphates, and contrins a large quantity of carbonate of ammonia. The case now began to clear up. To continue the quinine, and five minims of tincture of muriate of iron thrice a day; to which, on the 30 th, three minims of tincture of digitalis were added.

During the last fortnight of treatment he had five minims of tincture of muriate of iron and half a grain of disulphate of quinine three times a day. From the time he commenced the tonics his improvement was steady and rapid. He was discharged, quite well, on July 7 th; and fourteen days before, he was reported by his mother to be in much more perfect health than $h \mathrm{~h}$ had been for a long time, even than before his illness; he was much more lively, running about, and eating 
heartily. The abdomen also, the mother thought, was smaller than it had been before he was taken ill. The urine under the tonic treatment became more copious and acid, and ceased to effervesce with nitric acid. It was never found albuminous. On May 26 th the left flank was notably duller than the right, owing, no doubt, to distension of the cæcum and ascending colon. On May 30 th this was reversed, the left flank having become resonant and the right dull. Position, of course, was excluded as a cause. At the same date, the abdominal disten sion having diminished but little, the superficial abdominal veins were noted as large.

This case is a good evidence of the advantage of conducting treatment according to rational pathology, and not by mere routine. If diuretics had been persisted in the case would surely have ended badly. The timely administration of tonics, by giving vigour to the system, enabled the various organs, and amongst them the kidneys, to do their work better, and the result was a good recovery. The tonics were thus indirectly diuretics.

\section{ROYAL WESTMINSTER OPHTHALMIC HOSPITAL.}

ACUTE GLAUCOMA, SHOWING THE VALUE OF HANCOCK'S OPERATION OF DIVISION OF THE CILIARY MUSCLE.

(Under the care of Mr. HANCOCK.)

IN a former "Mirror," (The LANCET, vol. ii., 1859, p. 435, ) we placed upon record an example in which the most marked relief was afforded by the operation which now goes by the name of Mr. Hancock, and which consists of a division of the ciliary muscle. The nature of the operation, and the cases in which it is especially applicable, have been clearly set forth in Mr. Haneock's "Practical Clinical Remarks," which have appeared in two recent numbers of this journal, (vol. i. 1860, pp. 133 and 186,) to which we must refer our readers. The success which is there announced as having resulted from its adoption in several cases of acute and chronic glaucoma, and other intractable eye diseases, is most gratifying.

In the few remarks we made on first announcing Han cock's operation, we gave a short quotation upon Von Graefe's operation from the latest work on surgery then published, "Druitt's Surgeons' Vade-Mecum,"-a volume that generally contains all the latest information on surgery up to the time of the publication of its various editions. In a letter which subsequently appeared in our pages from Mr. Hulke, that gentleman appeared to forget that there was a quotation in our short remarks, and accorded to us the credit of giving a meagre and curtailed account of Graefe's operation. Mr. Hulke wrote as if he had sustained some very grave personal injury. We will merely observe, however, en passant, that Graefe's operation of iridectomy was to some extent anticipated many years before by the paracentesis oculi of Reverius, Middlemore, and Mackenzie ; for an account of the latter we would refer to the excellent treatise of the last surgeon "On Diseases of the Eye," p. 899, or to Mr. Hogg's useful work on the Ophthalmoscope, in which we find that the author is not sanguine of the ultimate value of iridectomy.

Of the value of Mr. Hancock's important and successful operation of division of the ciliary muscle, however, we have now abundant evidence; and to-day we record an illustration (selected from amongst a number in the Westminster Ophthalmic Hospital) which we had the opportunity of personally examining, and of witnessing the good effects produced, in a female of nearly sixty years of age, affected with acute glaucoma. The patient was blind on admision, but in three weeks she was able to read large-typed words in the Bible. It was a case well verifying Mr. Hancock's views.

A surgeon, recently writing from Paris, assured Mr. Hancock that he had the satisfaction of receiving M. Desmarres' testimony regarding the results of this operation in a case of glaucoma in which he had tried it. It wis described as a very bad case, and the effects of the operation were all that could be desired, quite as complete as after the performance of iridectomy. It was the intention of $M$. Desmarres to continue the practice, more especially in his bad cases, one-half of which he should treat by paracentesis, the other half by Mr. Hancock's method. In our "Purisian Medical Intelligence" for May 19th, the suc. cessful result of the latter procedure in a case of acute glau. coma of extreme severity, in the hands of M. Desmarres, is thus announced: "Within twelve hours of the operation all the symptoms had improved, and at the present moment (it is now five weeks since the event) the patient is fully as much benefited as if the most successful iridectomy had been performed." It will be seen, therefore, from the results already obtained in London and elsewhere, that the success of the operation is established, and Mr. Hancock has thus rendered a most important service to ophthalmic science.

For the notes of the following case we are indebted to Dr. Sansom, the medical registrar to the hospital :-

Harriet $\mathrm{B}-$, aged fifty-eight, was admitted into the hospital on the 21 st of March. She complained of intense pain in the right globe, and throbbing pain over the brow; the sight was wholly gone; the conjunctiva was greatly congested; the sclerotic presented a purplish glow; the pupil was dilated and irregular, and the lens opaque and disorganized, presenting a greenish appearance. The light used for ophthalmoscopic examination could not penetrate the disorganized lens. The eyeball was exceedingly tense, but the slightest pressure caused most severe pain. The patient was thin and pale, and presented the appearance of having undergone much suffering. Fer previous history was as follows:-She had never had any disease of the eye until the present attack. Three months ago the eye watered as if she had caught cold in it, but she paid little attention to this. Occasionally, towards evening, she experienced the sensation of flashes of fire before the eye, and the flame of the candle seemed surrounded by a halo of colour, but all unpleasant symptoms disappeared towards morning. On the 14th of March (a week before admission) it rapidly became worse, great pain occurred over the brow, and a tense throbbing pain referred to the back of the orbit. The eye, she said, seemed so tight that it would burst. The symptoms continued to increase.

On March 23rd, Mr. Hancock divided the ciliary ligament, and a quantity of fluid and disorganized vitreous humour escaped. The eye was kept from the light.

March 26th. - The pain has entirely left her; she is able to tell the number of fingers held up before the eye which has been operated on, the other being closed; the iris has been slightly drawn into the wound.

30th.-Pain continues entirely absent. She can now distin. guish the outline of any object, and she says that the sight is improving every day.

\section{CHARING.CROSS HOSPITAL.}

CONICAL CORNEA, IMPAIRED VISION, AND SHORT SIGHT; NOCTURNAL PAIN AND MORNING LACHRYMATION; HANCOCK'S OPERATION FOLLOWED BY GOOD RESULTS.

(Under the care of Mr. Hancock.)

The cases in which division of the ciliary muscle has been resorted to are hydrophthalmia, sclerotic staphylomata, and. acute and chronic glaucoma. It has also been performed in conical cornea by Mr. Power in a female patient, aged twentyeight, at the Royal Westminster Ophthalmic Hospital, whose case is given in Mr. Hancock's "Practical Clinical Remarks," already referred to. The following is another example of the same affection, in which the good results of its adoption have proved most satisfactory, and for the brief notes of which we are indebted to the house-surgeon of the Charing-cross Hos. pital :-

Ellen J__ aged sixteen years, admitted into the above hospital on March 27th, 1S60. She states that up to the age of three years her sight was good; but at that period she suffered from measles, which was followed by whooping-cough. From that time to the present her vision has become more and more impaired, so that before the operation she could not see the largest letters upon sign-boards at the distance of a yard or two, and when reading she was obliged to hold the book close to her eyes. She also suffered greatly from pain in her eyes at night and profuse lachrymation in the morning. The cornea of each eye is conical in form.

On April 12th, Mr. Hancock divided the ciliary muscle of the right eye, with great relief of the pain and improvement of vision. On April 28th, the ciliary muscle of the left eye was divided with the same success, so that the patient now has tolerable vision, being able to read a book at eight or nine inches' distance from her eyes; the cornea also looks much flattened. Concave glasses do not afford her any relief, but cause objects to appear more indistinct. 